\title{
REVISITING THE APOLLO PHOTOGRAMMETRIC MAPPING SYSTEM
}

\author{
K.L. Edmundson ${ }^{1, *}$, O. Alexandrov ${ }^{2}$, B.A. Archinal ${ }^{1}$, K.J. Becker ${ }^{3}$, T.L. Becker ${ }^{3}$, J.A. Mapel ${ }^{1}$, Z.M. Moratto ${ }^{4}$, A.V. Nefian ${ }^{2}$, J.O. \\ Richie $^{1}$, M.S. Robinson ${ }^{5}$, M.R. Shepherd ${ }^{1}$, J.R. Shinaman ${ }^{1}$, and E.D. Smith ${ }^{1}$ \\ ${ }^{1}$ U.S. Geological Survey, Astrogeology Science Center, Flagstaff, AZ, USA, 86001 - kedmundson@usgs.gov \\ 2 NASA Ames Research Center, Moffett Field, CA, USA, 94035 - oleg.alexandrov@nasa.gov \\ ${ }^{3}$ Lunar \& Planetary Laboratory, University of Arizona, Tucson, Arizona, USA, 85705 - tbecker@orex.lpl.arizona.edu \\ ${ }^{4}$ Google Inc., Mountain View, California, USA, 94043 - zmoratto@gmail.com \\ ${ }^{5}$ School of Earth and Space Exploration, Arizona State University, Tempe, Arizona, USA, 85287 - robinson@ser.asu.edu
}

Commission I, WG I/2

KEY WORDS: Apollo, Mapping Systems, Metric Camera, Panoramic Camera, Photogrammetry

\begin{abstract}
:
The integrated photogrammetric mapping system flown on the last three Apollo lunar missions (AS15, AS16, and AS17) in 1971 and 1972 incorporated a Metric (mapping) Camera, a high-resolution Panoramic Camera, and a star camera and laser altimeter. The U.S. Geological Survey’s Astrogeology Science Center, the Intelligent Robotics Group of the NASA Ames Research Center, and Arizona State University are working together in an ongoing collaboration to achieve the most complete cartographic development of Apollo mapping system data into versatile digital map products. These will enable a variety of scientific/engineering uses of the data including mission planning, geologic mapping, geophysical process modelling, slope dependent correction of spectral data, and change detection. After a brief discussion of the origins of the mapping system, we describe the Metric and Panoramic cameras, processing of the associated image and support data, work to photogrammetrically control the Metric Camera images, and future plans.
\end{abstract}

\section{INTRODUCTION}

In 1967, the Summer Study of Lunar Science and Exploration convened to examine various topics in lunar science and to compile recommendations for science operations and supporting instrumentation for both the later and post-Apollo lunar missions (NASA, 1967). The Geodesy and Cartography Working Group (GCWG) at this meeting concluded that "the most serious deficiency in available knowledge of the lunar surface profile is adequate geodetic control over the total Moon or fractions thereof.” To rectify this, the group recommended a 28-day polar mission to the Moon incorporating 1) a metric frame camera; 2) two convergent, long focal-length panoramic cameras to complement the metric camera with high-resolution stereo photography of regions of scientific or operational interest; 3) two stellar cameras for absolute orientation; and 4) a laser altimeter supporting the camera systems with precise range measurements between image exposure stations and the lunar surface.

In hindsight, it is perhaps not surprising that the instrumentation recommended by the GCWG was very close to that flown on the 120 successful and highly classified photo reconnaissance missions operated by the United States Air Force and CIA between 1959 and 1972 under the codename Corona (Day, Logsdon, and Latell, 1998; Figure 1). Although primarily for reconnaissance of the former Soviet Union and China, the Corona program (declassified between 1995 and 2002) acquired highresolution images around the globe. Today, available to the public, these images remain valuable for environmental and other investigations.

Ultimately, the integrated photogrammetric mapping system flown on the last three Apollo lunar missions (AS15, AS16, and

\footnotetext{
* Corresponding author
}

AS17) in 1971 and 1972 did utilize instruments adapted from Corona. This system included a Metric (mapping) Camera (MC), one high-resolution Panoramic Camera (PC), one stellar camera, and a laser altimeter (Figure 2; Table 1; Livingston, et al., 1980).

Camera coverage from the three missions was limited to the illuminated portion of the near-equatorial zone spanning the ground tracks of the three missions. From pre-flight analyses and in situ observations and measurements obtained by the landed Apollo missions (e.g., Masursky et al., 1978), this zone encompasses perhaps the most studied portion of the Moon. These analyses have established a fundamental baseline for lunar surface characterization that is unmatched in other regions.

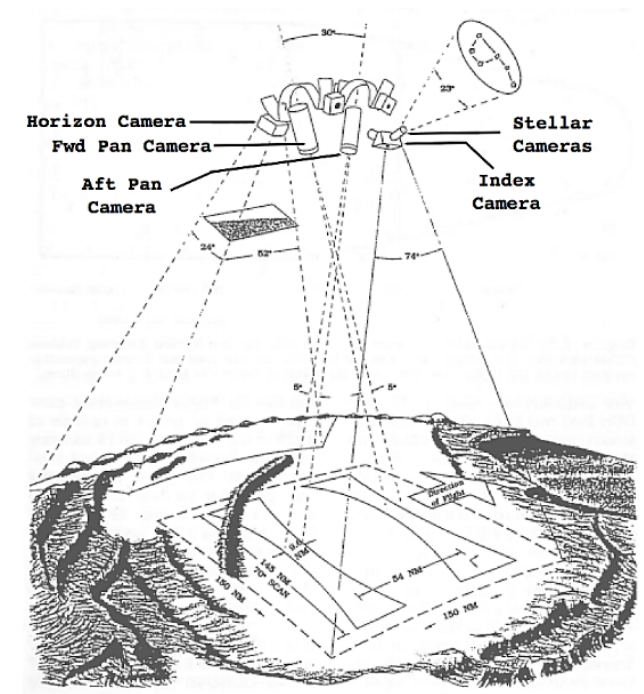

Figure 1: Corona KH-4B camera configuration and ground coverage (from Day, 1998). 


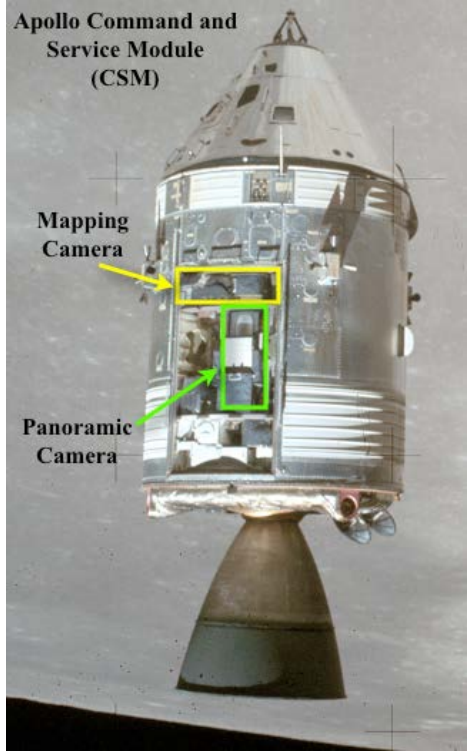

Figure 2: Apollo 15 Command and Service Module with Lunar Mapping Camera System and Panoramic Camera in the Scientific Instrument Module (from NASA image AS15-88-11972).

Approximately 6,000 MC and 4500 PC images suitable for mapping were acquired by the three missions. They cover $\sim 25 \%$ and $\sim 20 \%$ of the Moon respectively. Like the Corona images, Apollo mapping system data remain relevant and highly valuable today. For example, the resolution of the PC approaches that of the Lunar Reconnaissance Orbiter (LRO) Narrow Angle Camera. Other than a few Lunar Orbiter and Ranger images and images from landed missions, these are the highest resolution images acquired before LRO and offer a unique and invaluable opportunity for the detection of subtle changes in the lunar surface over a $\sim 45$-year window in time.
In the years after the Apollo missions, several U.S. government agencies (e.g. Defense Mapping Agency, National Oceanic and Atmospheric Administration, U.S. Geological Survey [USGS], and NASA) worked to geodetically control primarily the nadir MC photographs, producing hardcopy image mosaics and topographic contour maps (Doyle, Elassal, and Lucas, 1976; Light, et al., 1980). Clearly, hardcopy products can’t be readily updated to be consistent with our rapidly improving knowledge of lunar coordinates and they do not support the quantitative and detailed surface characterization needed for future landed missions. Consequently, in an ongoing collaboration, the USGS Astrogeology Science Center (ASC), Arizona State University (ASU), and the Intelligent Robotics Group of the NASA Ames Research Center (ARC) are working to achieve the most complete cartographic development of Apollo mapping system data into versatile digital map products. This will enable a variety of scientific/engineering uses of the data including mission planning, geologic mapping, geophysical process modelling, slope dependent correction of spectral data, and change detection.

Below we describe the Metric and Panoramic cameras, processing of the associated image and support data, and work thus far to photogrammetrically control the MC images. Finally, we summarize future plans.

\section{THE METRIC CAMERA}

The Lunar Mapping Camera, manufactured by the Space and Defense Systems branch of the Fairchild Camera and Instrument Corporation, consisted of the MC, stellar camera, and laser altimeter integrated into a single unit (Figure 3). The MC was a frame camera similar to those used in terrestrial aerial photogrammetry (Doyle, 1970). Accurately calibrated prior to flight, it had a focal length of $76 \mathrm{~mm}$ and an image format of 114 square $\mathrm{mm}$.

Table 1: Apollo camera characteristics (from Light, 1972).

\begin{tabular}{|c|c|c|c|}
\hline \multirow{2}{*}{$\begin{array}{l}\text { Characteristics } \\
\text { Manufacturer }\end{array}$} & \multicolumn{2}{|c|}{ Mapping Camera System } & Terrain Analysis \\
\hline & $\begin{array}{l}\text { Fairchild camera \& } \\
\text { Instrument Corp. }\end{array}$ & $\begin{array}{l}\text { Fairchild camera \& } \\
\text { Instrument Corp. }\end{array}$ & $\begin{array}{l}\text { Itek-Optical Systems } \\
\text { Division }\end{array}$ \\
\hline Basic design & Frame & Frame & Panoramic \\
\hline Focal length & 3 inches $(76.6 \mathrm{~mm})$ & 3 inches $(76 \mathrm{~mm})$ & 24 inches $(610 \mathrm{~mm})$ \\
\hline Lens angular coverage & $74^{\circ} \times 74^{\circ}$ & $24^{\circ} \times 18^{\circ}$ & $10^{\circ} 46^{\prime} \times 108^{\circ}$ \\
\hline Lens aperture & $f / 4.5$ & $f / 2.8$ & f $/ 3.5$ \\
\hline Lens distortion & $<50 \mu \mathrm{m}$ & $<10 \mu \mathrm{m}$ & - \\
\hline Filter & None & None & None \\
\hline Resolution $\mathrm{lp} / \mathrm{mm}$ & (a) $1.7: 1,58-70$ & To star magnitude 6 & (a) $2: 1,108-135$ \\
\hline Reseau-interval & $10 \mathrm{~mm}$ crosses (121) & $5 \mathrm{~mm}$ crosses (22) & $\overline{-1}$ \\
\hline $\begin{array}{l}\text { Illumination } \\
\text { Fiducials-Artificial }\end{array}$ & Natural & Artificial & Marlos \\
\hline $\begin{array}{l}\text { Fiducials-Artificial } \\
\text { Natural }\end{array}$ & $\begin{array}{l}2 \text { sets of } 4 \\
4\end{array}$ & $\stackrel{4}{\text { None }}$ & Marks \\
\hline Shutter Type & Between Lens & Between Lens & $\begin{array}{l}\text { Focal Plane-variable } \\
\text { slit }\end{array}$ \\
\hline Shutter speeds & $1 / 15$ to $1 / 240 \mathrm{sec}$. & 1.5 sec-fixed & $1 / 80$ to $1 / 500 \mathrm{sec}$. \\
\hline Format & $4.5 \times 4.5 \mathrm{in}$ & $0.88 \times 1.25$ in & $4.5 \times 45.25$ in \\
\hline Transmission & $44.3 \%$ & $93 \%$ & $55-78 \%$ \\
\hline $\begin{array}{l}\text { Film size and typical } \\
\text { type }\end{array}$ & $\begin{array}{l}5 \text { inches }(127 \mathrm{~mm}) \\
\text { Type EK } 3400 \text { or } \\
\text { EK } 3414\end{array}$ & $\begin{array}{l}1.38 \text { inches }(35 \mathrm{~mm}) \\
\text { (Non Perf.) Type } \\
3401\end{array}$ & $\begin{array}{l}5 \text { inches }(127 \mathrm{~mm}) \\
\text { Type EK } 3414\end{array}$ \\
\hline Magazine & 1500 feet & 510 feet & 6500 feet \\
\hline Capacity & (3600 frames) & (3600 frames) & (1617 frames) \\
\hline Cycling rate & 8.5 to $34 \mathrm{sec}$. & 8.5 to $34 \mathrm{sec}$. & 4.96 to $16.95 \mathrm{sec}$. \\
\hline Motion compensation & 10 to 40 M Radians/sec. & None & 10 to 20 M Radians/sec. \\
\hline Exposure control & 16:1 Automatic & Fixed (1.5 sec.) & $\begin{array}{l}\text { Automatic plus bias } \\
\text { tuning }\end{array}$ \\
\hline Weight & 131 Lbs W/Film & Total & 343 Lbs W/Film \\
\hline Data Recording & Data Block & Time; Serial No. & $\begin{array}{l}\text { GMT; Frame INCR; } \\
\mathrm{V} / \mathrm{h} \text { in } \mathrm{MR} / \mathrm{sec} \text {. }\end{array}$ \\
\hline Film Flattening & $\begin{array}{l}\text { Platen with moveable } \\
\text { pressure plate }\end{array}$ & $\begin{array}{l}\text { Platen with moveable } \\
\text { pressure plate }\end{array}$ & Rollers \\
\hline Stereo rock & - & - & $\pm 12 \frac{1}{2}^{\circ}$ plus IMC \\
\hline
\end{tabular}




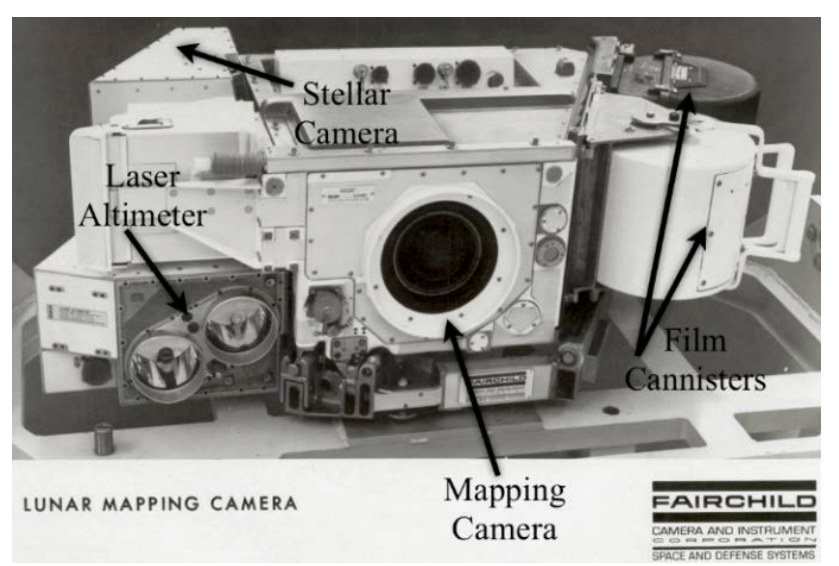

Figure 3: Apollo Lunar Mapping Camera System (NASA/Fairchild).

At the nominal altitude of $\sim 111 \mathrm{~km}$, a nadir MC image covers a region of $\sim 166 \times 166$ square $\mathrm{km}$. Along-track image overlap of $78 \%$ ensured sufficient stereo convergence and geometric strength for triangulation. Of the $\sim 6,000 \mathrm{MC}$ images suitable for mapping from AS15-17, 3/4 are nadir-looking, covering 16\% of the lunar surface. The remainder are oblique and increase useful coverage to $\sim 25 \%$.

\subsection{Data Preparation}

2.1.1 Film Scanning and Processing. The NASA Johnson Space Center (JSC) and ASU scanned the original MC and PC negatives (held in cold storage at JSC) at film-grain resolution (Robinson, et al., 2008; Paris, et al., 2012a). This summary closely follows that on the ASU Apollo Image Archive (apollo.sese.asu.edu/ABOUT_SCANS/index.html; accessed 12 July 2018). The film images were removed from cold storage, acclimated to room temperature, and hand-cleaned. Digitization was performed on a Leica DSW700 photogrammetric scanner (Calarco, Dam, and Walker, 2004) modified to record 14-bit to exploit the large dynamic range of the film. Scanned pixel size was $5 \mu \mathrm{m}$, corresponding to a ground sample distance of $\sim 8 \mathrm{~m}$ for the nadir MC images. Background (e.g. film base and fog) and vignetting were removed from the scans. Additional processing for the MC images included measuring and recording fiducial and reseau mark positions, image resampling to remove film deformation based on the reseau marks, and cosmetic removal of the reseau marks. Exposure information encoded on each film image as a pattern of dots in the margin was decoded and recorded. The processed scans were stored as 16-bit TIFF files.

2.1.2 Digitizing Support Data. ASU utilized optical character recognition software to convert hardcopy data from the Apollo-era reconstruction of spacecraft position and pointing for each image to digital form data (Paris, et al., 2012b). Most importantly this data included 1) exposure time (GMT); 2) the spacecraft state vector defined as the mean of the B1950 Moon centered, inertial, Cartesian coordinates of the spacecraft position and velocity; and 3) phi, omega, and kappa angles that rotate the camera axes coordinate system into the nadir point centered local horizontal system (NASA, 1972). Both ASU and the ASC worked to validate this information and manually corrected errors. Using this data, we generated a priori spacecraft position (sp) and image pointing (c) kernels for the MC images in NAIF SPICE format (Acton, 1996). For $~ 150$ otherwise useful AS15 MC images no support data was available. For these we determined a priori spacecraft position and image pointing via either interpolation or photogrammetric resection.

\subsection{Photogrammetric Control of Metric Camera Images}

2.2.1 Nadir Images. The ARC completed our joint project to process the nadir MC images from AS15-17, producing a photogrammetrically and geodetically controlled, orthorectified digital image mosaic (DIM) and digital terrain model (DTM) sampled at approximately $30 \mathrm{~m} /$ pixel (Nefian, et al., 2012, 2013) and tied to a reference frame based on Lunar Orbiter Laser Altimeter data (LOLA; Mazarico, et al., 2010). These products are available to the public through the NASA Moon Trek (formerly the Lunar Mapping and Modelling Project) Portal, https://moontrek.jpl.nasa.gov. This work was accomplished using the Ames Stereo Pipeline (ASP) software developed by the ARC (Moratto, et al., 2010) and the Integrated Software for Imagers and Spectrometers (ISIS3) planetary cartography package developed by the ASC (Keszthelyi, et al., 2014).

2.2.2 Apollo 15 Oblique Images. The ASC expanded upon the ARC's work by controlling the geometrically challenging oblique Apollo $15 \mathrm{MC}$ images to one another, to the nadir Apollo $15 \mathrm{MC}$ images, and to the LOLA reference frame as described by Edmundson, et al. (2016). There are 2350 useful MC images from AS15 alone, 475 of which are oblique. These were acquired in four orbits with the spacecraft oriented such that the camera was tilted either $25^{\circ}$ forward or aft; or $40^{\circ}$ north or south (orbits 23, 34, 35, and 71 respectively). In ISIS3, interest point detection and image matching are typically accomplished automatically with a minimal amount of operator intervention. Due to the highoblique geometry of orbits 35 and 71, considerable manual work was required to edit inaccurate image measurements or incorrect matches, particularly between these and the nadir orbits.

Products from this work included 1) a database of MC tie points and their adjusted coordinates for the Apollo 15 region consistent with the LOLA reference frame; 2) Apollo 15 spacecraft position and image pointing kernels, both derived from original Apollo tracking data and updated from control network solutions; and 3) a DTM (produced by the ARC), individual orbit DIMs, and combined DIMs of the Apollo 15 region including both nadir and oblique MC coverage and sampled at $\sim 30 \mathrm{~m} /$ pixel. The quality of the DTM and DIMs worsens with increasing obliqueness (i.e. toward the limb). Therefore, we trimmed the DTM and the oblique orbit and combined mosaics at an emission angle of $\sim 80^{\circ}$. The tie point database, DTM, and DIMs will soon be available through the USGS Astrogeology PDS Annex data portal, http:// astrogeology.usgs.gov/pds/annex. Updated and a priori position and pointing kernels are now available to the community via the ASC ISIS3 public release.

\section{THE PANORAMIC CAMERA}

The PC (Figure 4), manufactured by the Itek Corporation, was modified from the Itek KA-80A "optical bar" camera used by the Air Force (McCash, 1973). This camera (610 mm focal length; image format $127 \mathrm{~mm}$ along-track by $1.2 \mathrm{~m}$ across-track) was incorporated into a complex, highly dynamic assembly which not only enabled the camera to sweep $108^{\circ}$ across-track for image acquisition, but also pivoted the camera every other exposure $12.5^{\circ}$ forward and aft about a gimbal to achieve stereo coverage (Figure 5). PC images were acquired either simultaneously or interleaved with the MC images. A single image covers a $22 \mathrm{~km}$ (along-track) by $339 \mathrm{~km}$ (across-track) swath on the lunar surface. 


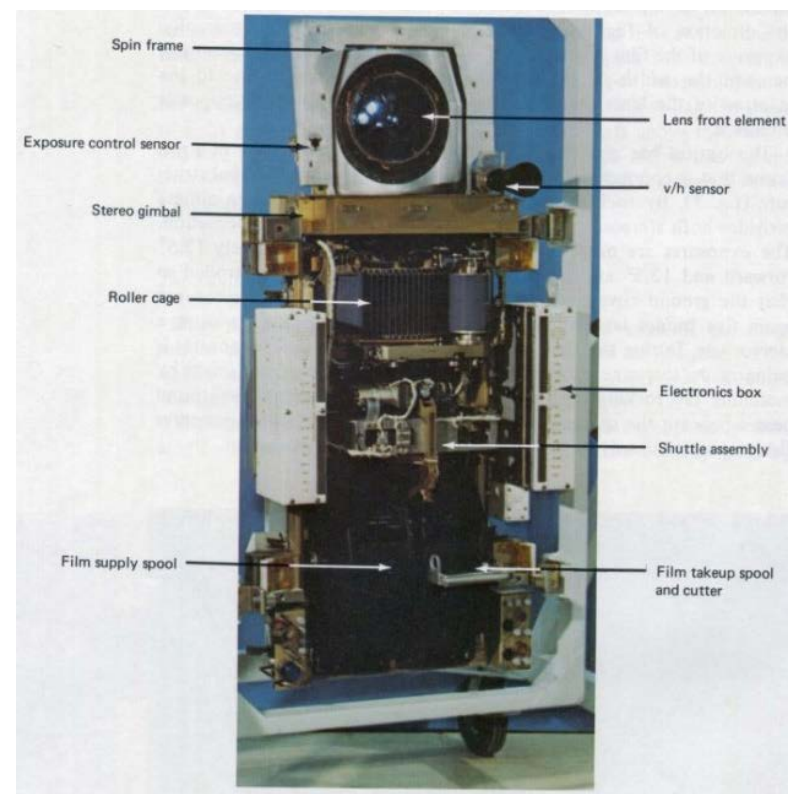

Figure 4: Apollo Panoramic Camera with cover removed (NASA).

During image acquisition, the optical system rotated clockwise about an axis parallel to the flight direction while the film moved through the camera in the opposite direction. The film was exposed through a variable width slit that, similar to a pushbroom camera, defines the instantaneous focal plane. The horizontal image coordinate determines the time of exposure, establishing camera position and pointing at that time. Image motion compensation (IMC), to minimize blur from the camera's forward motion, was implemented by tilting the entire assembly continuously backward about the stereo gimbal during exposure. A row of fiducial marks was exposed on the film above and below the image data, defining the image coordinate system. To photogrammetrically control PC images requires a precise estimate of time throughout the exposure due to the dynamic nature of the camera. This was accomplished by exposing a row of timing marks on the film below the bottom row of fiducials (Case, 1967; Figure 6). The timing marks consisted of a sequence of dashes of varying length, in a modified IRIG-B time code format (Range Commanders Council, 2004). The code records at

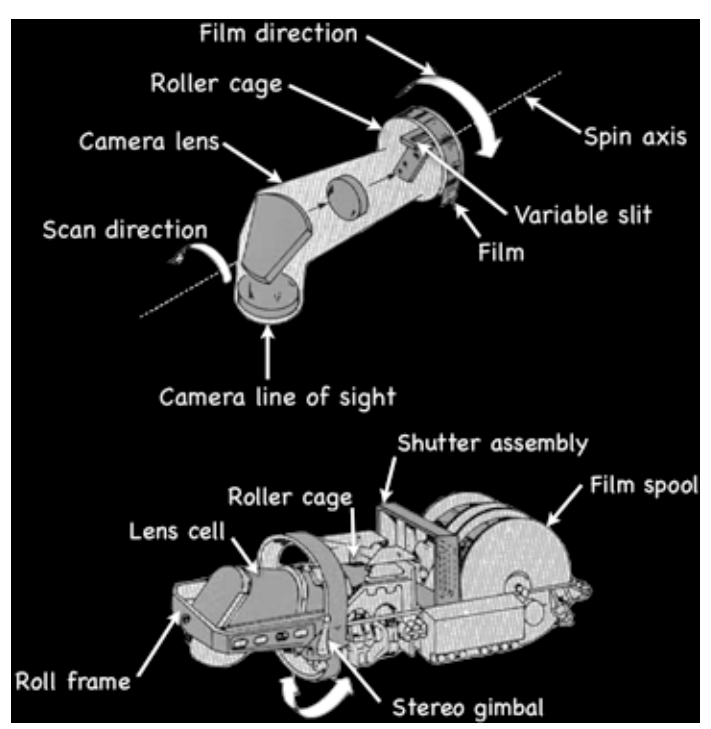

Figure 5: Top - PC roll frame assembly. Bottom - Stereo gimbal (NASA).

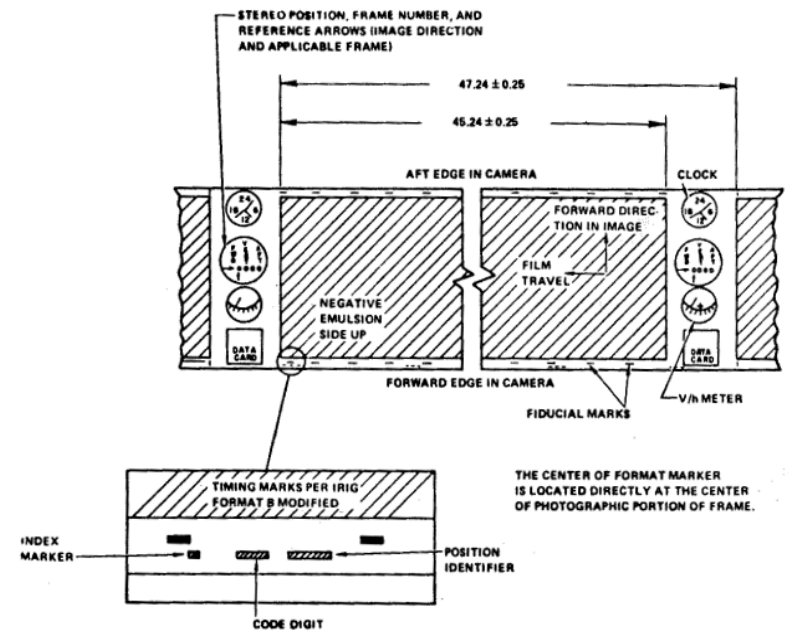

Figure 6: PC film format (from NASA, 1971b, Fig. 4-3).

every full second, the complete time after launch in seconds, minutes, hours, and days. Additional marks are made at 10 millisecond increments between full seconds.

The $V / H$ (velocity/altitude) sensor, which determined the rate of apparent motion of the ground scene, regulated camera cycling rate, exposure, and IMC (McCash, 1973). These values were in general variable and subject to error. On Apollo 15 this was aggravated by a drifting $V / H$ sensor that would reset after wandering out of its normal operating range (NASA, 1971a). In some images this error is clearly visible as a sudden change in exposure, in the length of timing marks, and in the spacing between them.

\subsection{Sensor Model Derivation}

Below we summarize the development of the PC sensor model, following closely Jackson et al. (1982). For a dynamic camera such as the PC, a separate photographic coordinate system (identical to a frame camera) can be constructed at each instant of time throughout image acquisition. The system origin is located at the intersection of the optical axis with the instantaneous exposure station (Figure 7) The positive image $x-$ axis is in the flight direction. From Figure 7 (left),

$$
\begin{aligned}
& x^{\prime}=x-x_{p} \\
& y^{\prime}=0 \\
& z^{\prime}=-f
\end{aligned}
$$

$\begin{array}{ll}x_{p} & \text { is the principal point offset } \\ f & \text { is the focal length }\end{array}$

This instantaneous system is rotated into a local nadir coordinate system (Figure 7 , right) through the scan angle $\theta$ about the image $x$-axis, referenced to the scan center. The scan angle is the product of the scan rate and the exposure time (defined by the $y$ image coordinate), also referenced to the scan center.

The scan angle matrix $R_{\theta}$ is given as

$$
R_{\theta}=\left[\begin{array}{ccc}
1 & 0 & 0 \\
0 & \cos \theta & -\sin \theta \\
0 & \sin \theta & \cos \theta
\end{array}\right]
$$



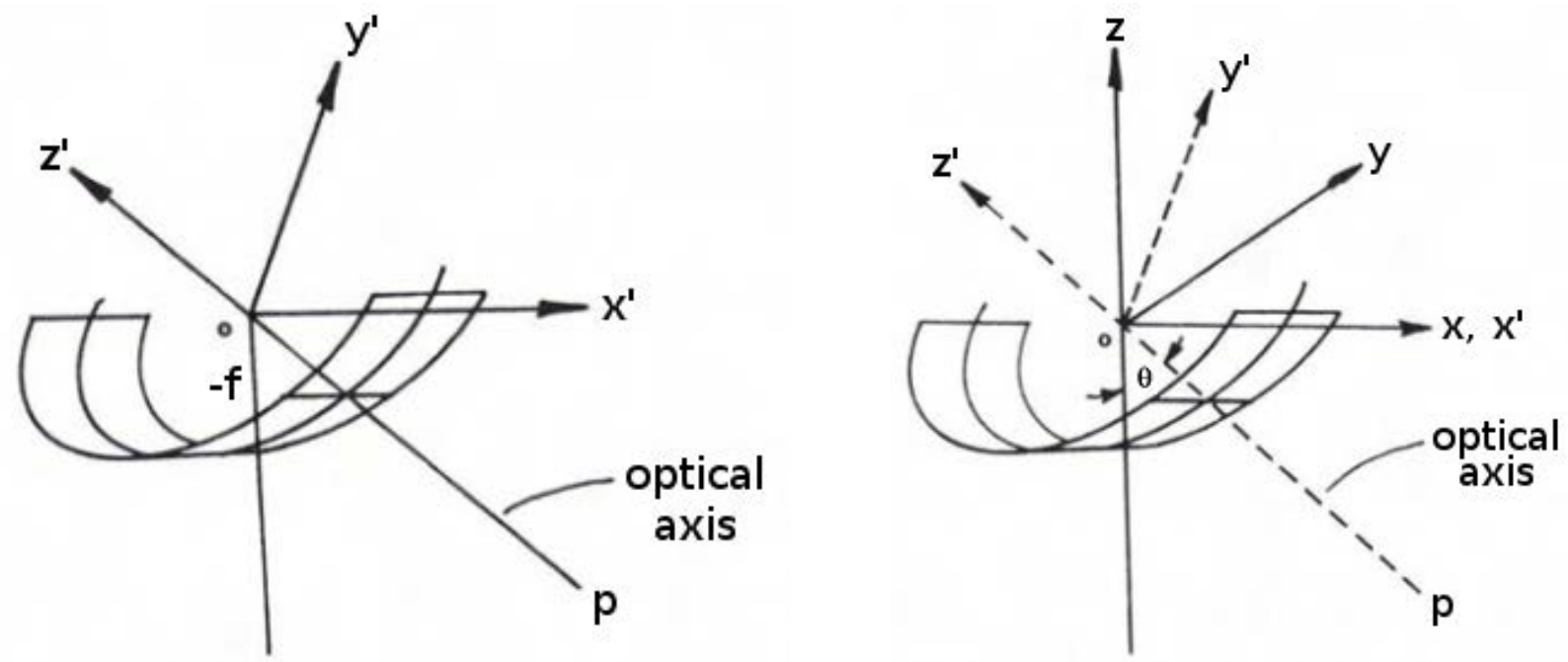

Figure 7: The scan angle $\theta$ rotates the instantaneous coordinate system on the left into the local nadir coordinate system on the right. From Jackson et al. (1982).

The collinearity condition for a frame camera is

$$
\left[\begin{array}{c}
x_{i} \\
y_{i} \\
-f
\end{array}\right]=K R_{\phi} R_{\omega} R_{\kappa}\left[\begin{array}{c}
X_{i}-X_{c} \\
Y_{i}-Y_{c} \\
Z_{i}-Z_{c}
\end{array}\right]
$$

$\begin{array}{ll}f & \begin{array}{l}\text { is the focal length } \\ \text { are image coordinates of point } i \\ x_{i}, y_{i}\end{array} \\ K & \begin{array}{l}\text { is a scaling constant } \\ R_{\phi} R_{\omega} R_{\kappa}\end{array} \\ X_{c}, Y_{c}, Z_{c} & \begin{array}{l}\text { is the ground to photo rotation } \\ \text { matrix }\end{array} \\ X_{i}, Y_{i}, Z_{i} & \begin{array}{l}\text { axposure station } \\ \text { exe object coordinates of point } i\end{array}\end{array}$

The collinearity condition for each instantaneous photographic coordinate system for the PC becomes

$$
\left[\begin{array}{c}
x_{i} \\
0 \\
-f
\end{array}\right]=K R_{\theta}^{T} R_{\phi} R_{\omega} R_{\kappa}\left[\begin{array}{c}
X_{i}-X_{c i} \\
Y_{i}-Y_{c i} \\
Z_{i}-Z_{c i}
\end{array}\right]
$$

where

$$
\begin{aligned}
& X_{c i}=X_{c 0}+\dot{X}_{c} y_{i} \\
& Y_{c i}=Y_{c 0}+\dot{Y}_{c} y_{i} \\
& Z_{c i}=Z_{c 0}+\dot{Z}_{c} y_{i}
\end{aligned}
$$

and

$$
\begin{array}{ll}
X_{c 0}, Y_{c 0}, Z_{c 0} & \begin{array}{l}
\text { are the instantaneous camera } \\
\text { coordinates at scan center, time } y_{0}
\end{array} \\
X_{c i}, Y_{c i}, Z_{c i} & \begin{array}{l}
\text { are the instantaneous camera } \\
\text { coordinates at point } i \text {, time } y_{i}
\end{array} \\
\dot{X}_{c}, \dot{Y}_{c}, \dot{Z}_{c} & \text { are components of camera velocity }
\end{array}
$$

As mentioned above, image motion compensation (IMC) is implemented by tilting the PC backward about the camera $y$-axis. At any instantaneous photographic coordinate system the change in the $\phi$ rotation angle due to IMC is given as

$$
\Delta \phi=\frac{V}{H} y_{i}
$$

where

$$
\begin{array}{ll}
V & \text { is spacecraft velocity } \\
H & \text { is spacecraft altitude }
\end{array}
$$

The complete $\phi$ rotation angle at any time is

$$
\phi=\phi_{0}+\Delta \phi
$$

$$
\text { where } \quad \phi_{0} \text { is } \phi \text { at the scan center }
$$

\subsection{Data Preparation}

3.2.1 Film Scanning and Processing. Film scanning was accomplished as described above for the MC image data. Due to the large physical and scanned file size of the PC images ( 16 Gb), each PC scan was stored as 8 separate, overlapping $2 \mathrm{~Gb}$ image tiles. The scanned pixel size of $5 \mu \mathrm{m}$ corresponds to $\sim 2 \mathrm{~m}$ at the center of a nadir PC image and $\sim 5 \mathrm{~m}$ at the extents.

3.2.2 Detecting Fiducial and Timing Marks. Fiducial and timing marks are automatically detected in all 8 image tiles with the OpenCV computer vision library (Bradski, 2000). The Canny edge detection operator is used to locate and extract mark boundaries (Canny, 1983; Figure 8). The pixel location of the center of mass of each boundary is computed and stored, along with the boundary itself. The pixel locations of the beginning and end of each timing mark are stored as well. Known approximate mark dimensions are used to filter out erroneously detected marks. In some cases, marks are difficult to distinguish from a bright surrounding background which hinders detection. We have found that this can be remedied by passing a boxcar filter over the region prior to detection, enhancing the mark (Eliason and McEwen, 1990).

\subsubsection{Matching Fiducial and Timing Marks Across} Overlapping Image Tiles. Scanning the PC image into 8 overlapping tiles is advantageous for storage. Because the fiducial and timing mark patterns span the entire image, tiling also complicates their identification. After detecting timing marks in each individual tile, the modified IRIG-B pattern is decoded using the Jenk's Natural Breaks Algorithm (Jenks, 1967). Fiducial and timing marks are matched in the overlap between tiles by

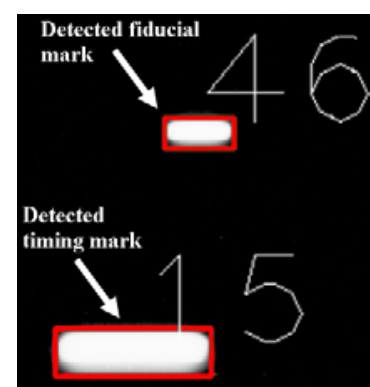

Figure 8: Automatically detected fiducial and timing marks. 
walking the patterns over one another virtually, until the match is confirmed. Fiducial mark ids are confirmed by affine transformation to their known coordinates. Outliers are flagged based on their residuals from the transformation. Errors in detection, matching, and identification of marks are corrected manually. Final pixel locations of the beginning and end of timing marks and of fiducial mark centers are stored in the ISIS3 image labels.

The decoded timing marks are used to compute exposure rates at each column across the entire image. These rates are stored in a table on the ISIS3 image in a format comparable to run-length encoding. Each line in the table indicates a change in exposure rate and contains the column (or sample) where the rate changed, ephemeris time, and new exposure rate.

3.2.4 Support Data. Support data for the PC images is the same as the MC except that the exposure time, state vector, and image rotation angles are defined at the center of the image swath. A priori spacecraft position kernels established for the MC images can be directly applied to the PC images. The image rotation angles change continuously through the image due to the camera sweep and IMC. Because of this, generating PC $a$ priori pointing kernels is more complicated than for the MC. In addition to the above support data, the spacecraft velocity and altitude are also required. We determine the scan angle matrix $R_{\theta}$ (Eq. 2) and the $\phi$ rotation matrix updated for IMC (Eq. 7) at a number of times throughout the scan and with these compute the full rotation matrix $R_{\theta}^{T} R_{\phi} R_{\omega} R_{\kappa}$ (Eq. 4) at these times. These rotation matrices are then used to create the pointing kernel (e.g. Figure 9).

\section{ONGOING AND FUTURE WORK}

We have recently completed the creation of a priori position and pointing SPICE kernels for the Apollo 15 PC and will shortly begin the process of controlling these images. Ultimately, we hope to control all MC and PC images from AS15, AS16, and AS17.

\section{ACKNOWLEDGMENTS}

Work on MC and PC data is funded by the NASA Lunar Advanced Science and Exploration Research program under contracts \#NNH12AU53I and \#NNH14AY48I respectively. Any use of trade, firm, or product names is for descriptive purposes only and does not imply endorsement by the U.S. Government.

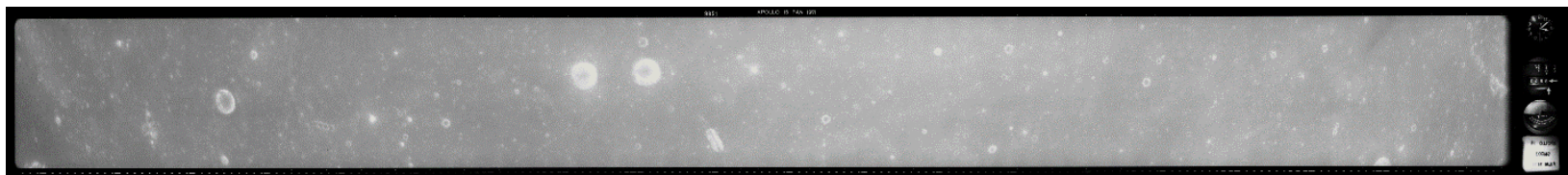

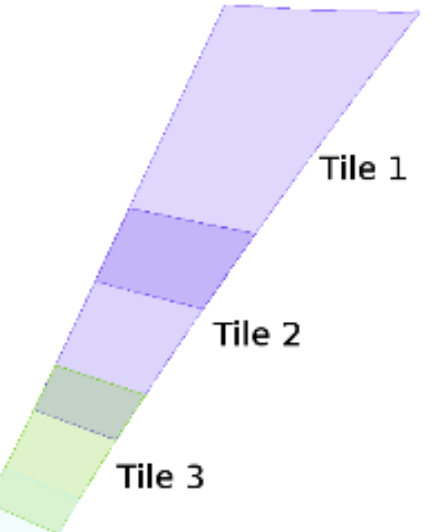

Tile 4

Tile 5

Tile 6

Tile 7

Tile 8

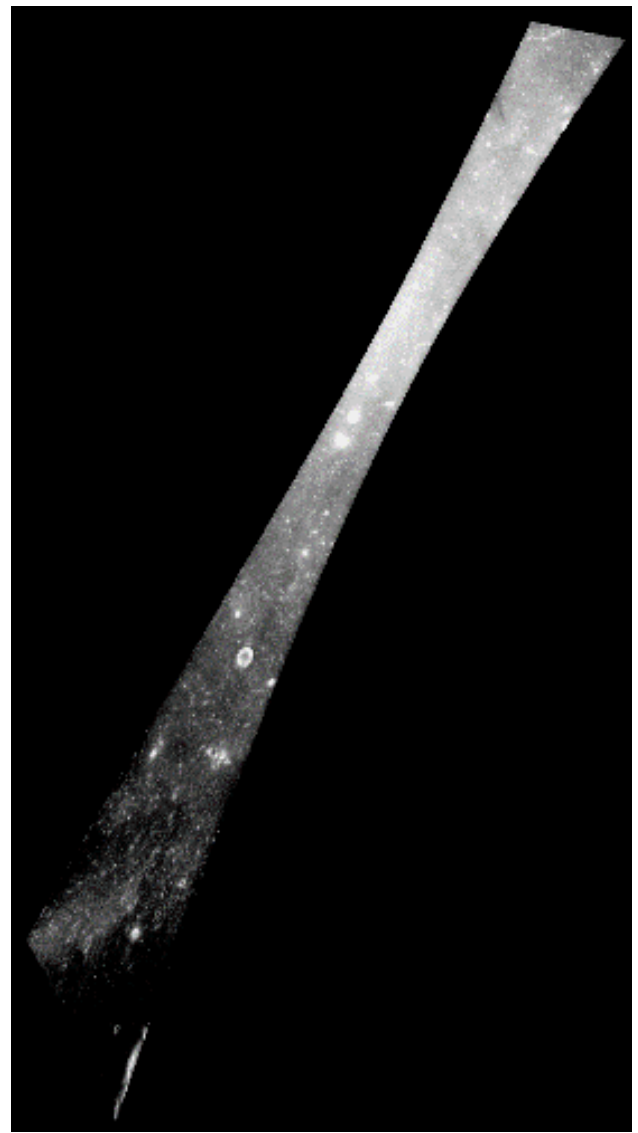

Figure 9: Top - Apollo 15 PC image AS15-P-9851, oriented $12.5^{\circ}$ aft and centered at $\sim 10^{\circ} .78 \mathrm{~S}, 34^{\circ} .04 \mathrm{E}$ over Mare Tranquillitatis (NASA/JSC/ASU). Projected footprints (bottom left) and mosaic (bottom right) of image tiles 1-8 after application of $a$ priori position and pointing kernels. Projection is Equirectangular. 


\section{REFERENCES}

Acton, C.H., 1996. Ancillary Data Services of NASA's Navigation and Ancillary Information Facility. Planetary and Space Science, 44(1), pp. 65-70.

Bradski, G., 2000. The OpenCV Library, Dr. Dobbs Journal of Software Tools, 25(11) pp. 122-125.

Calarco, A., Dam, A., and Walker, S.A., 2004. Geometric Precision of Scanned Imagery for Production Photogrammetry. Int. Arch. Photogramm. Rem. Sens. Spatial Info. Sci., 34(3).

Canny, J.F., 1983. Finding Edges and Lines in Images. MIT Artificial Intell. Lab., Cambridge, MA, Tech. Rpt. AI-TR-720, 145 pages.

Case, J.B., 1967. The Analytical Reduction of Panoramic and Strip Photography. Photogrammetria. 22(4), pp. 127-141.

Day, D.A.,1998. “Mapping the Dark Side of the World.”, Part 2, Spaceflight, 40, No. 8, pp. 303-310.

Day, D.A., Logsdon, J.M., and Latell, B. (eds.), 1998. Eye in the Sky: The Story of the Corona Spy Satellites. Smithsonian Institution Press, Washington and London.

Doyle, F.J., 1970. Photographic Systems for Apollo. Photogramm. Eng., 36(10), pp. 1039-1044.

Doyle, F., Elassal, A., and Lucas, J., 1976. Experiment S-213 Selenocentric Geodetic Reference System. Geodetic Research and Development Laboratory, National Oceanic and Atmospheric Administration, Rockville, MD, and Topographic Division, U.S. Geological Survey, Reston, VA. Final Report. July.

Edmundson, K.L, Alexandrov, O., Archinal, B.A., Becker, K.J. Becker, T.L., Kirk, R.L., Moratto, Z.M., Nefian, A.V., Richie, J., and Robinson, M.R., 2016. Photogrammetric Processing of Apollo 15 Metric Camera Oblique Images. ISPRS Int. Arch. Photogramm. Remote Sens. Spatial Inf. Sci., XLI(B4), pp. 375381.

Eliason, E.M. and McEwen, A.S., 1990. Adaptive Box Filters for Removal of Random Noise from Digital Images. Photogramm. Eng. Remote Sens. 56(4), 453-458.

Jackson, M., Greve, C., Hoffman, G., and Ackerman, D., 1982. A Parameterization of the Itek KA-80A Panoramic Camera. Photogramm. Eng. Remote Sensing, 48(5), pp. 761-769.

Jenks, G.F., 1967. The Data Model Concept in Statistical Mapping. International Yearbook of Cartography, 7, pp. 186190.

Keszthelyi, K., Becker, T., Titus, T., Sides, S., Gaddis, L., Hare, T., Kirk, R., Edmundson, K., and Anderson, J., 2014. Utilizing the Integrated Software for Imagers and Spectrometers (ISIS) to Support Future Missions. Lunar and Planet Sci. XLV, Abstract 1686.

Light, D.L., 1972. Photo Geodesy from Apollo. Photogramm. Eng., 38(6), pp. 574-587.

Light, D.L., Brown, D., Colvocoresses, A.P., Doyle, F.J., Davies, M., Ellasal, A., Junkins, J.L., Manent, J.R., McKenney, A., Undrejka, R., and Wood, G., 1980. Coordinates Derived from Apollo Metric Camera Photographs. In Manual of Photogrammetry, 4th Edition, C.C. Slama, C. Theurer, and S.W.
Henriksen, Editors. American Society of Photogrammetry, Falls Church, VA, pp. 935-936.

Livingston, R.G., Berndsen, C.E., Ondrejka, R., Spriggs, R.M., Kosofsky, L.J., Van Steenburgh, D., Norton, C., Brown, D., 1980. Aerial Cameras. In Manual of Photogrammetry, $4^{\text {th }}$ Edition, C.C. Slama, C. Theurer, and S.W. Henriksen, Editors. American Society of Photogrammetry, Falls Church, VA, pp. 187-278.

Masursky, H., Colton, G.W., and El-Baz, F., (eds.), 1978. Apollo Over the Moon - A View from Orbit, NASA, Washington, D.C., SP-362.

Mazarico, E., Neumann, G.A., Rowlands, D.D., and Smith, D.E., 2010. Geodetic constraints from multi-beam laser altimeter crossovers. Journal of Geodesy, 84(6), pp. 343-354.

McCash, D.K., 1973. Apollo 15 Panoramic Photographs. Photogramm. Eng., 39(1), pp. 65-72.

Moratto, Z.M., Broxton, M.J., Beyer, R.A., Lundy, R.A., and Husmann, K., 2010. Ames Stereo Pipeline, NASA's Open Source Automated Stereogrammetry Software. Lunar and Planet Sci. XLI, Abstract 2364.

NASA, 1967. 1967 Summer Study of Lunar Science and Exploration, 31 July to 13 August, University. of CaliforniaSanta Cruz, NASA SP-157, 394 pages. [online] Available at: https://ntrs.nasa.gov/archive/nasa/casi.ntrs.nasa.gov/196700312 35.pdf [Accessed 12 July, 2018].

NASA, 1971a. Apollo Mission 15 Mission Report. Prepared under the Direction of the Department of Defense by the Aeronautical Chart and Information Center, US Air Force. Photography Index Compiled by Manned Spacecraft Center, Mapping Sciences Branch (March, 1972). [online] Available at: <www.lpi.usra.edu/resources/mapcatalog/apolloindex/apollo15/ as15indexmap02/> [Accessed 12 July 2018].

NASA, 1971b. Apollo 15 Sim Bay Photographic Equipment and Mission Summary. Prepared by Mapping Sciences Branch, Manned Spacecraft Center (August, 1971). [online] Available at: $<$ http://apollo.sese.asu.edu/SUPPORT_DATA/

AS15_SIMBAY_SUMMARY.pdf> [Accessed 12 July 2018].

NASA, 1972. Apollo 15 Photograph Evaluation (APE) Data Book. Compiled by Manned Spacecraft Center, Mathematical Physics Branch, Mission Planning and Analysis Division (June 13, 1972). [online] Available at: < http:// apollo.sese.asu.edu/ SUPPORT_DATA/Apollo15_APE_Data_Book.pdf $>$ [Accessed 12 July 2018].

Nefian, A.V., Moratto, Z., Beyer, R., Kim, T., Broxton, M., and Fong, T., 2012. Apollo Metric Zone Terrain Reconstruction. Lunar Planet Sci., XLIII, Abstract 2184.

Nefian, A.V., Alexandrov, O., Kim, T., Moratto, Z., and Beyer, R., 2013. Albedo Reconstruction of the Apollo Metric Camera Zone. Lunar Planet Sci., XLIV, Abstract 1649.

Paris, K.N., Robinson, M.S., Lawrence, S.J., Danton, J., Bowman-Cisneros, E., Licht, A., Close, W., and Ingram, R., 2012a. The Apollo Digital Image Archive: Project Status. Lunar Planet Sci., XLIII, Abstract 2273. 
Paris, K.N., Licht, A., Robinson, M.S., Bowman-Cisneros, E., and Williams, D., 2012b. Apollo Ephemeris Data. In Gaddis, L.R., Hare, T., and Beyer, R., eds. 2014. Summary of Abstracts of the Planetary Data Workshop, June 2012. U.S. Geological Survey Open-File Report 2014-1056. 199 p. [online] Available at: <http://dx.doi.org/10.3133/ofr20141056> [Accessed 12 July, 2018].

Range Commanders Council, 2004. IRIG Serial Time Code Formats, IRIG Standard 200-04. [online] Available at: $<$ http://irigb.com/pdf/wp-irig-200-04.pdf> [Accessed 12 July, 2018].

Robinson, M.S., Lawrence, S.J., Close, W., Bode, R., Grunsfeld, J.M., Ingram, R., Jefferson, L., Locke, S., Mitchell, R., Scarsella, T., White, M., Hager, M.A., Mackwell, S., Watters, T.R., Bowman-Cisneros, E., Danton, J., Speyerer, E., Dam, A., Calarco, A., and Garvin, J., 2008. The Apollo Digital Image Archive. Lunar and Planet Sci. XXXIX, Abstract 1515. 